Gut, 1987, 28, 1673-1681

\title{
Clinical and ultrastructural studies in duodenal pseudomelanosis
}

\author{
J Y KANG, A Y T WU, J L S CHIA, A WEE, I H SUTHERLAND, AND \\ R HORI
}

From the Departments of Medicine, Pathology, and Zoology, National University of Singapore and the Department of Renal Medicine, Singapore General Hospital, Singapore

SUMMARY Nine patients with duodenal pseudomelanosis are described: seven had endstage renal failure while one other patient had undergone renal transplantation. Eight of the nine had been on oral iron supplements. The pigment stained positively with Perls' stain for iron in five patients, positively with the Masson-Fontana method normally used to identify melanin in one, and positively with both methods in three. Electron probe $x$-ray analysis of the pigment on samples from six patients showed iron to be present in all six, while sulphur was present in five. Varying sulphur content of the pigment in different patients could account for differences in histochemical characteristics. Iron was also shown in the duodenal biopsies of 34 of 48 uraemic patients on oral iron supplements, but was present in only 22 of 120 patients endoscoped for miscellaneous conditions $(p<0 \cdot 001)$. We postulate that the pigment of duodenal pseudomelanosis is derived from iron absorbed from the lumen.

The presence of a spotty brownish or blackish pigmentation in the duodenal mucosa at endoscopy, termed duodenal melanosis or pseudomelanosis, has been described in eight previous case reports. ${ }^{1-s}$ Histochemically, the pigment appeared to contain either iron, melanin like substances, or both. Its pathogenesis and significance, however, remain obscure. We describe here nine patients with this condition in whom clinical, histological, ultrastructural, and electron probe $\mathrm{x}$-ray analytical studies have been carried out. For comparison, duodenal biopsies from 48 other patients on maintenance haemodialysis, and 120 patients endoscoped for miscellaneous conditions were also studied.

\section{Case reports}

All nine patients were Chinese: five women and four men. Diagnosis was made in seven patients during routine pretransplant evaluation of patients with endstage renal failure and undergoing maintenance

Address for correspondence: Dr J Y Kang. Department of Medicine. National University Hospital. Lower Kent Ridge Road. Singapore 0511

Received for publication 20 February 1987. peritoneal or haemodialysis. Two of the seven reported dyspeptic symptoms while the others had no abdominal complaints. Patient 8 had undergone a cadaveric renal transplant after having been on maintenance haemodialysis for three years. Postoperatively, she developed upper gastrointestinal haemorrhage. Gastroduodenoscopy revealed a gastric ulcer as well as duodenal pigmentation. Patient 9 presented with upper abdominal discomfort and normochromic, normocytic anaemia and duodenal pigmentation was noted at endoscopy. All nine patients denied regular purgative intake and sigmoidoscopy in six showed no melanosis coli. Patients $1-8$ had been on regular iron supplements while patient 9, being anaemic, could also have received oral iron therapy before coming to our attention. Other clinical data and endoscopic findings are listed in Table 1.

The colour of the duodenal pigment varied from brown to black. It was spotty in distribution, usually maximal in the second part of the duodenum, extending as far as the endoscope could reach. The duodenal bulb was usually affected to a lesser extent.

The duodenal pigmentation in patients 1,2 , and 3 
Table 1 Patient characteristics

\begin{tabular}{|c|c|c|c|c|}
\hline Patient & Sexiage & History & Drugs (previous/current) & Other endoscopic findings \\
\hline 1 & $\mathrm{M} / 33$ & $\begin{array}{l}\text { Hacmodialysis } \\
5 \text { years (dyspeptic) }\end{array}$ & $\begin{array}{l}\text { Ferrous sulphate, calcium, vitamins, propranolol, } \\
\text { chlorothiazide, methyldopa }\end{array}$ & $\begin{array}{l}\text { Patch of blackish pigment in } \\
\text { lower gastric body }\end{array}$ \\
\hline 2 & $\mathrm{M} / 47$ & $\begin{array}{l}\text { Hacmodialysis } \\
18 \text { months }\end{array}$ & Ferrous sulphate, vitamins, aluminum hydroxide & Lipid island in antrum \\
\hline 3 & $\mathrm{~F} / 44$ & $\begin{array}{l}\text { Hacmodialysis } \\
2 \text { years }\end{array}$ & $\begin{array}{l}\text { Ferrous sulphate, vitamins, calcium. cotrimoxazole, } \\
\text { calcium }\end{array}$ & \\
\hline 4 & $\mathrm{M} / 34$ & $\begin{array}{l}\text { Haemodialysis } \\
3 \text { years }\end{array}$ & Ferrous sulphate, vitamins, propranolol. hydrallazine & \\
\hline 5 & $\mathrm{~F} / 51$ & $\begin{array}{l}\text { Peritoneal dialysis } \\
3 \text { years (abdominal pain) }\end{array}$ & $\begin{array}{l}\text { Ferrous sulphate, vitamins, calcium, aluminium } \\
\text { hydroxide, sodium bicarbonate, methyldopa. } \\
\text { propranolol, theophylline, hydrallazine }\end{array}$ & \\
\hline 6 & $\mathrm{M} / 14$ & $\begin{array}{l}\text { Peritoneal dialysis } \\
16 \text { months }\end{array}$ & $\begin{array}{l}\text { Ferrous sulphate, vitamins, calcium. prochlorperazine. } \\
\text { propranolol, fusidic acid, Amikacin. Vancomycin }\end{array}$ & Petechiac in antrum \\
\hline 7 & $\mathrm{~F} / 17$ & $\begin{array}{l}\text { Peritoneal dialysis } \\
28 \text { months }\end{array}$ & $\begin{array}{l}\text { Ferrous sulphate, vitamihs, chlorothiazide, propranolol. } \\
\text { hydrallazine, cyclophosphamide, dipyridamole, warfarin }\end{array}$ & \\
\hline 8 & $F / 28$ & $\begin{array}{l}\text { Hacmodialysis } \\
3 \text { years Post-transplant }\end{array}$ & $\begin{array}{l}\text { Ferrous sulphate, vitamins, methyldopa, propranolol, } \\
\text { hydrallazine, azathioprine, nifedepine, prednisolone }\end{array}$ & Gastric ulcer \\
\hline 9 & $\mathrm{~F} / 79$ & $\begin{array}{l}\text { Anaemic, abdominal } \\
\text { discomfort }\end{array}$ & & \\
\hline
\end{tabular}

was found to be unchanged on repeat endoscopy one year later. The gastric pigment originally seen in patient 1 , however, was not present at repeat endoscopy. In patient 4 repeat examination after 15 months showed complete disappearance of duodenal pigmentation. In patient 8 , repeat duodenoscopy 13 months after initial presentation showed persistent duodenal pigmentation. Its staining characteristics had altered however (Table 2). Patients 5, 6 and 7 had not had repeat endoscopy while patient nine defaulted from follow up.

\section{Methods}

\section{LIGHT MICROSCOPY}

In all cases, biopsies were taken from the second part of the duodenum. Formalin fixed, paraffin embedded histological sections were stained with haematoxylin and eosin, periodic acid - Schiff stain, Perls' Prussian blue method for iron, Masson-Fontana method usually used to show melanin, and the Fouchet method for bile. In addition, unstained histologic sections were examined for autofluorescence at $450 \mathrm{~m} \mu$. In patients $1,6,7$, and 8 (second biopsy) the stains for iron and melanin were also done on sections which had been bleached with potassium permanganate.

\section{ELECTRON MICROSCOPY}

In six patients (patients $1,3,5,6,7$ and 8 - second biopsy), duodenal specimens were fixed in $2 \%$ buffered glutaraldehyde at $4^{\circ} \mathrm{C}$ for one hour. They were then cut into $1 \mathrm{~mm}^{3}$ pieces and fixed for a further one hour. After rinsing the tissues in phosphate buffer they were postfixed in $1 \%$ buffered osmium tetroxide for three hours at $4^{\circ} \mathrm{C}$. Dehydration was carried out using increasing concentrations of acetone. The tissues were then left in a mixture of

Table 2 Pigment staining characteristics

\begin{tabular}{|c|c|c|c|c|c|c|c|}
\hline Patient number & $\begin{array}{l}\text { Masson- } \\
\text { Fontana } \\
\text { (melanin) }\end{array}$ & $\begin{array}{l}\text { Masson- } \\
\text { Fontana after } \\
\text { bleaching }\end{array}$ & $P A S$ & $\begin{array}{l}\text { Auto- } \\
\text { fluorescence } \\
\text { (lipofuscin) }\end{array}$ & $\begin{array}{l}\text { Fouchet } \\
\text { method } \\
\text { (bile) }\end{array}$ & $\begin{array}{l}\text { Perls' } \\
\text { Prussian blue } \\
\text { (iron) }\end{array}$ & $\begin{array}{l}\text { Perls' } \\
\text { Prussian blue } \\
\text { after bleaching }\end{array}$ \\
\hline 1 Duodenal & + & - & - & - & - & - & - \\
\hline Gastric & - & & - & - & - & + & \\
\hline 2 Duodenal & - & & + & - & - & + & \\
\hline 3 Duodenal & - & & + & - & - & + & \\
\hline 4 Duodenal & - & & - & - & - & + & \\
\hline 5 Duodenal & - & & - & - & - & + & \\
\hline 6 Duodenal & + & - & + & - & - & + & + \\
\hline 7 Duodenal & + & - & + & - & - & + & + \\
\hline 8 First duodenal biopsy & - & & + & - & - & + & \\
\hline Second duodenal biopsy & + & - & + & - & - & + & + \\
\hline 9 Duodenal & - & & - & - & - & + & \\
\hline
\end{tabular}


Araldite $M$ and acetone (9:1) overnight. Final embedding was done the following day and the blocks left to polymerise at $60^{\circ} \mathrm{C}$ for 18 hours. Semithin sections from these blocks were cut, using glass knives, on a Reichert Ultracut E microtome. The sections were stained in a methylene blue-azure II solution and examined under the light microscope to locate areas of pigmentation. Ultrathin sections of about $80 \mathrm{~nm}$ were then cut, using diamond knives, and mounted on 200 mesh formvar coated copper grids. Some of the grids were stained with uranyl acetate followed by lead citrate and examined with a Philips 400 transmission electron microscope.

\section{ELECTRON PROBE X-RAY ANALYSIS}

This technique permits identification of elements contained in minute areas within the cell. We were therefore able to identify the elements present in the pigment of duodenal pseudomelanosis.

Unstained sections from the same blocks as those used for electron microscopy were subjected to electron-probe $\mathrm{x}$-ray microanalysis in a JEOL $100 \mathrm{CX}$ scanning/transmission electron microscope (accelerating voltage $60 \mathrm{kV}$ ) to which was interfaced a computerised energy dispersive $\mathrm{x}$-ray spectrometer (Link systems 860 series 2 ). X-ray counts on both the angular and rounded electron dense bodies were collected for a period of 600 seconds live time. The spectra obtained and displayed on the cathode ray screen were photographed. Areas in the vicinity of the dense bodies were similarly analysed as controls. Electron micrographs were taken of the areas analysed.

\section{CONTROL PATIENTS}

Forty eight consecutive patients on maintenance haemodialysis who were undergoing gastroduodenoscopy as part of their pretransplant assessment and in whom the duodenum was macroscopically normal were studied. One biopsy was taken from each patient and stained for iron using the Perls' stain. Duodenal biopsies from the second part were also taken from 120 consecutive patients undergoing gastroduodenoscopy for miscellaneous conditions. These were also stained for iron in the same way.

Two of us (AW and IHS) graded the iron content of the duodenal biopsies independently, on a scale from 0 to $3+$. If no iron granules were identified, the grade was 0 . Specimens with sparse granules or a few isolated clusters of granules were graded $1+$, specimens with iron granules in a moderate number of macrophages were graded 2+ (Fig. 1c), and heavy iron staining was graded $3+$ (Fig. $2 \mathrm{c}$ ). In order to determine the reproducibility of this method of assessment, the grades from 47 consecutive biopsies were compared.
Informed consent was obtained from each patient. The present studies were carried out in accordance with the Declaration of Helsinki. The $\chi^{2}$ test was used for statistical analysis.

\section{Results}

\section{L.IGHT MICROSCOPY}

The pigment appeared as golden to yellowish brown, fine or coarse granules, mainly within macrophages in the lamina propria. A smaller amount was extracellular. Staining characteristics are shown in Table 2 . Three patterns were observed. The pigment in patients $2,3,4,5,8$ (on the first occasion) and 9 was positive with the Perls' stain and negative with the Masson-Fontana method (Fig. 2). In contrast, the pigment in patient 1 was negative with Perls' stain, positive with the Masson-Fontana method, but becoming negative after bleaching. The pigment in patients 6,7 , and 8 (second biopsy) was positive by both the Masson-Fontana method and the Perls stain (Fig. 1): after bleaching, the pigment became negative with the Masson-Fontana method but the iron stain remained positive.

\section{ELECTRON MICROSCOPY}

Representative electron photomicrographs are shown in Figures 3 and 4. In patients 1, 6,7 and 8. angular membrane bound, electron dense structures similar to those previously described ${ }^{2 n \times}$ were present. In addition, patient 8 also exhibited irregularly shaped structures. In patients 3 and 5, rounded or irregularly shaped electron dense structures could be seen. In some areas, these structures were slightly angular and seemed to be contained within lysosomal bodies.

ELECTRON PROBE X-RAY ANALYSIS (Figs. 5-8)

All specimens showed peaks of copper and osmium from the grids and fixative respectively. In addition, the angular structures in patients $1,6,7$ and 8 contained iron and sulphur (iron:sulphur ratio $=$ $1: 1 \cdot 17,1: 0 \cdot 84,1: 0 \cdot 41$ and $1:(0 \cdot 64$ respectively). The more rounded structures in patient 5 also contained iron with a smaller amount of sulphur (ratio = $1: 0 \cdot 15)$. The rounded structures in patient 3 contained only iron and no sulphur was detectable. Control areas gave no significant counts for either iron or sulphur.

CONTROI. PATIENTS

Of the 48 dialysis patients whose duodenal biopsies were stained for iron, $34(71 \%)$ were positive. (Grade $1+20$ patients; grade $2+12$ patients; grade $3+2$ patients). In contrast, only 22 of 120 duodenal biopsies $(18 \%)$ in patients endoscoped for miscel- 
Fig. 1 (a) (Case 6, second biopsy). Brownish black granules present within macrophages located in the duodenal villous cores.

(haematoxylin \& eosin); (b) the pigment was positive for melanin like material (grade 2+) (MassonFontana method); (c) The pigment was also positive for iron (grade $2+)$ (Perl's stain).
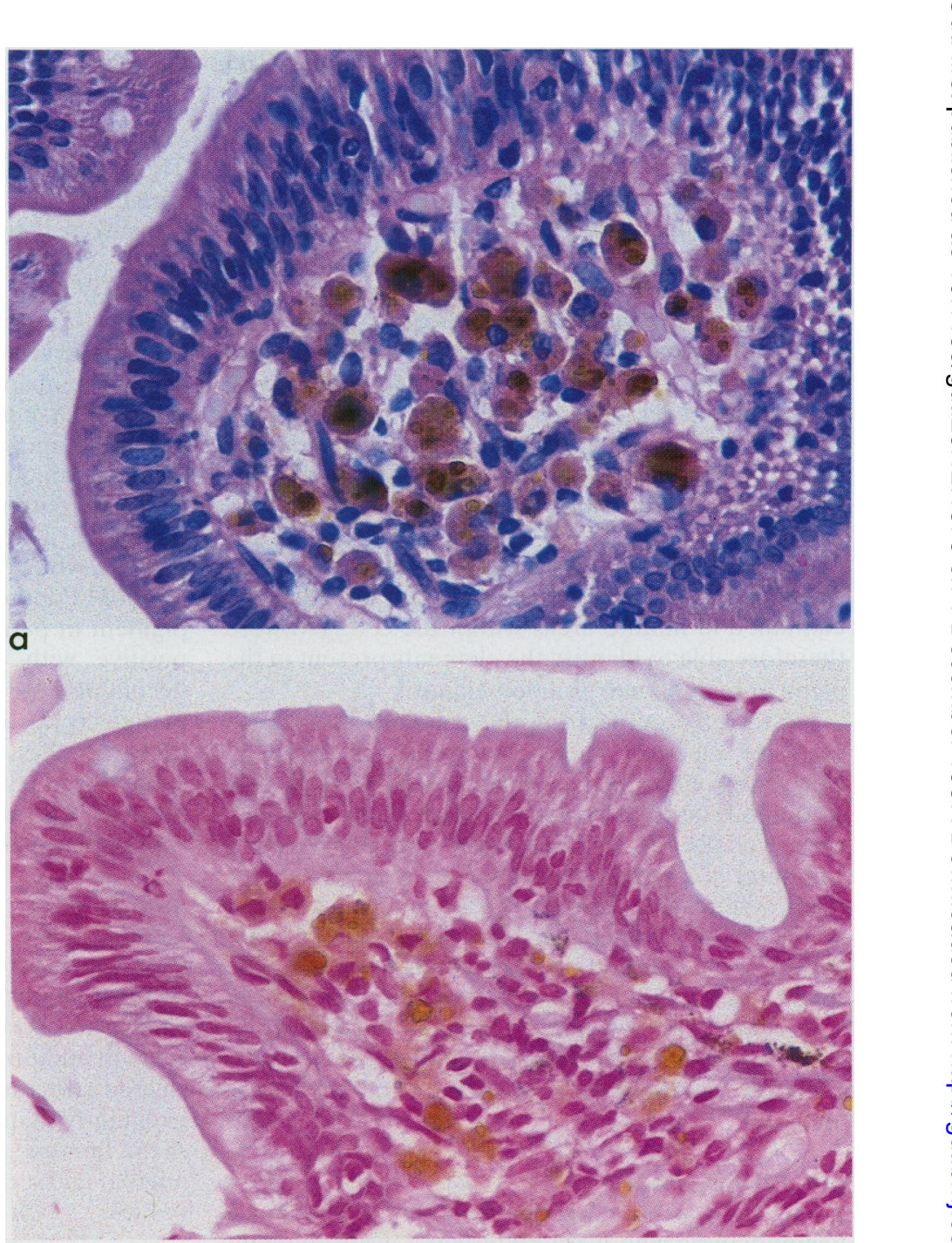

b

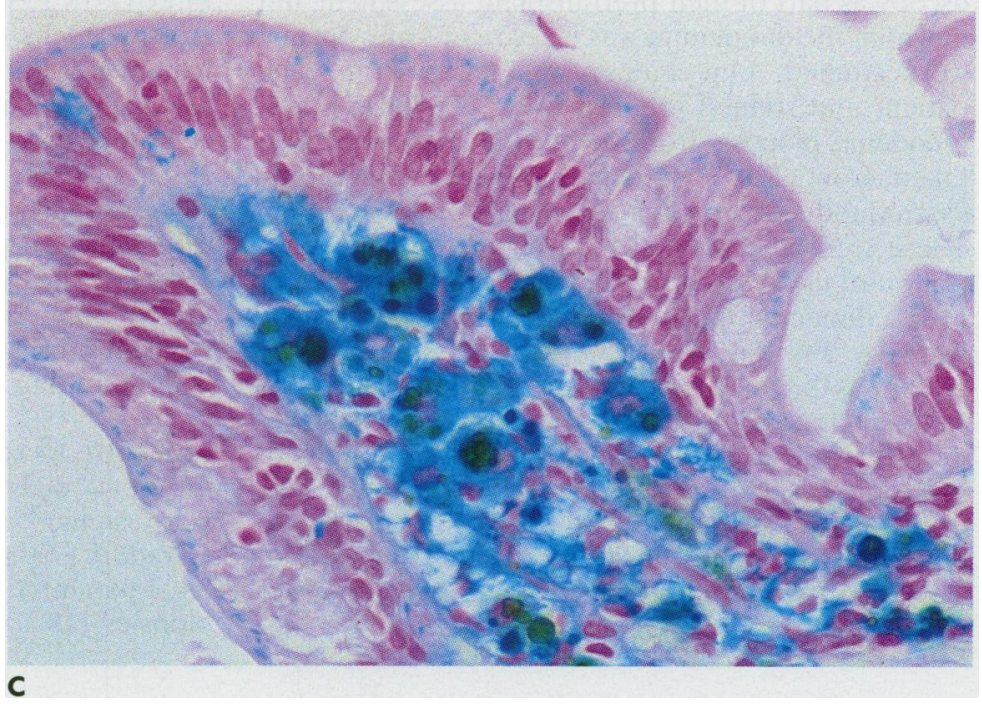




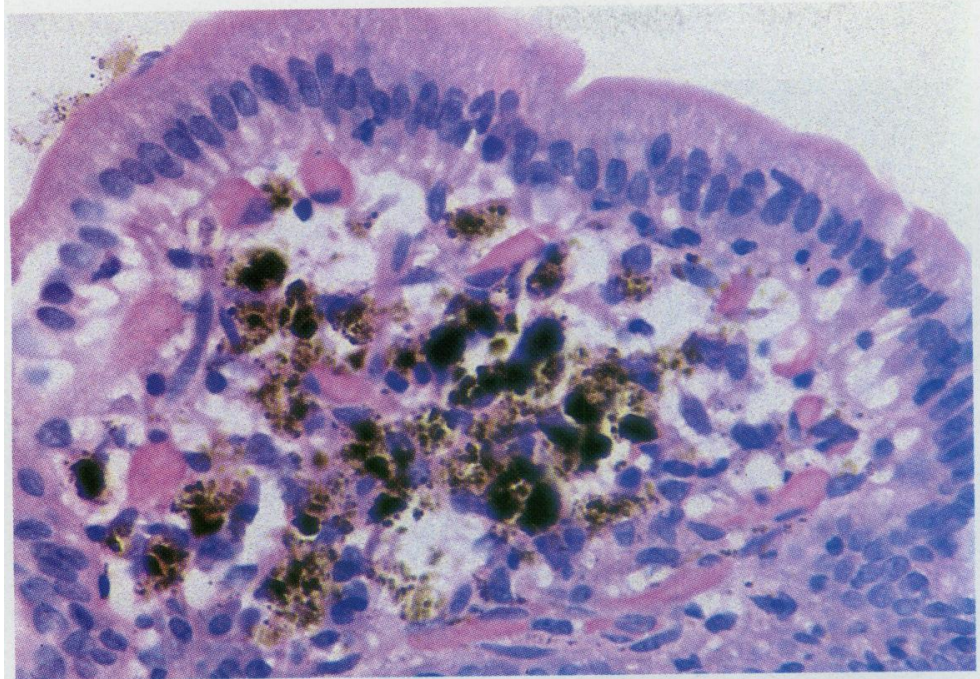

1677

a

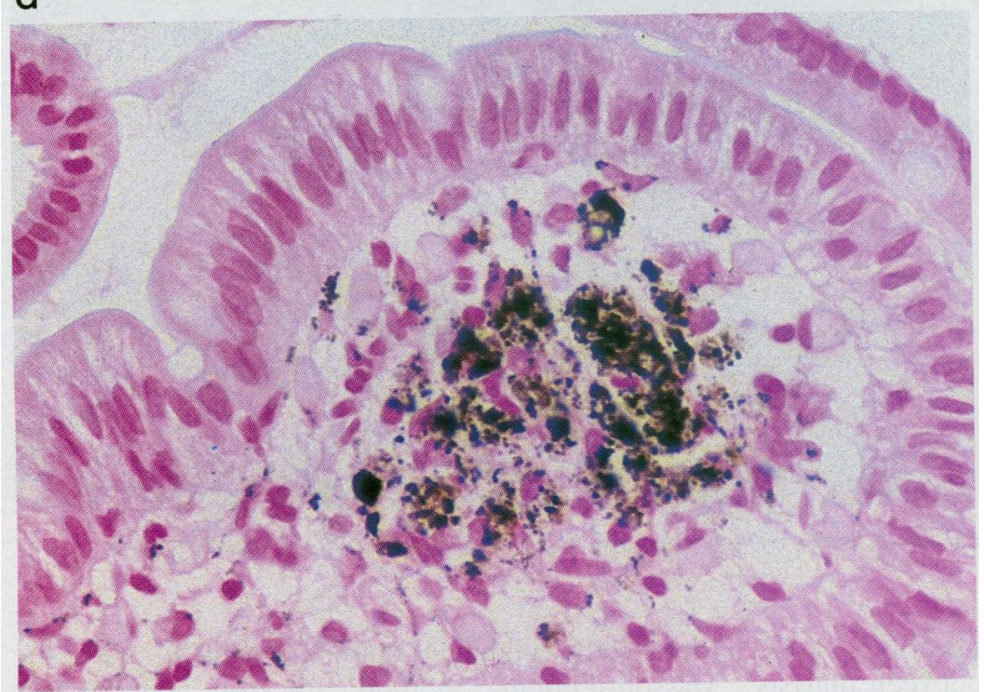

Fig. 2(a) (Case 3). Dark brown granules present within macrophages located in the duodenal villous cores (haematoxylin \& eosin); (b) the pigment was negative for melanin like material (grade 0) (MassonFontana method); (c) The pigment was positive for iron (grade $3+$ ) (Perl's stain).

b

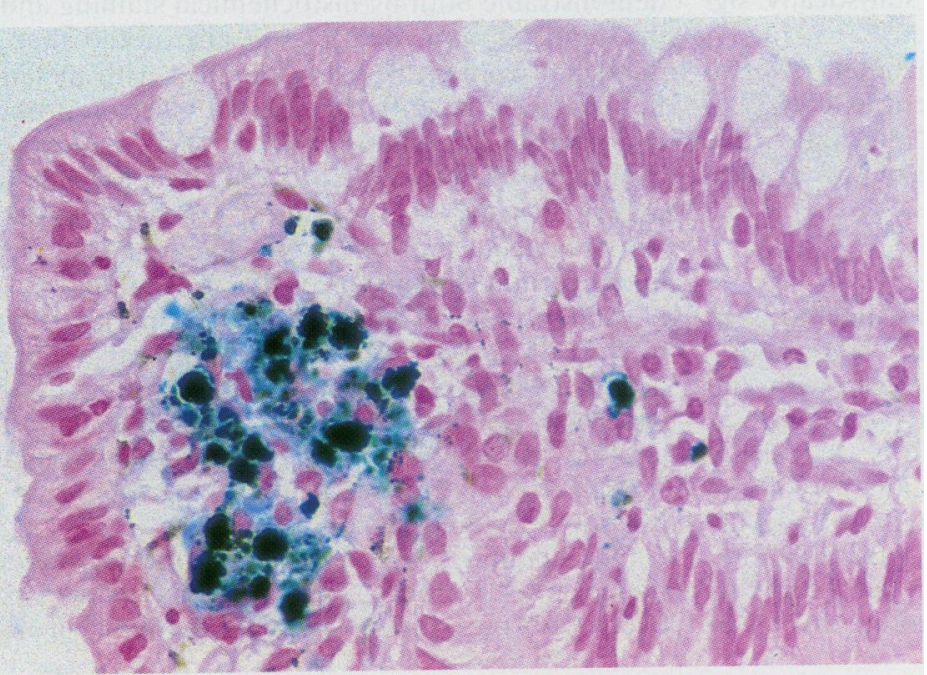




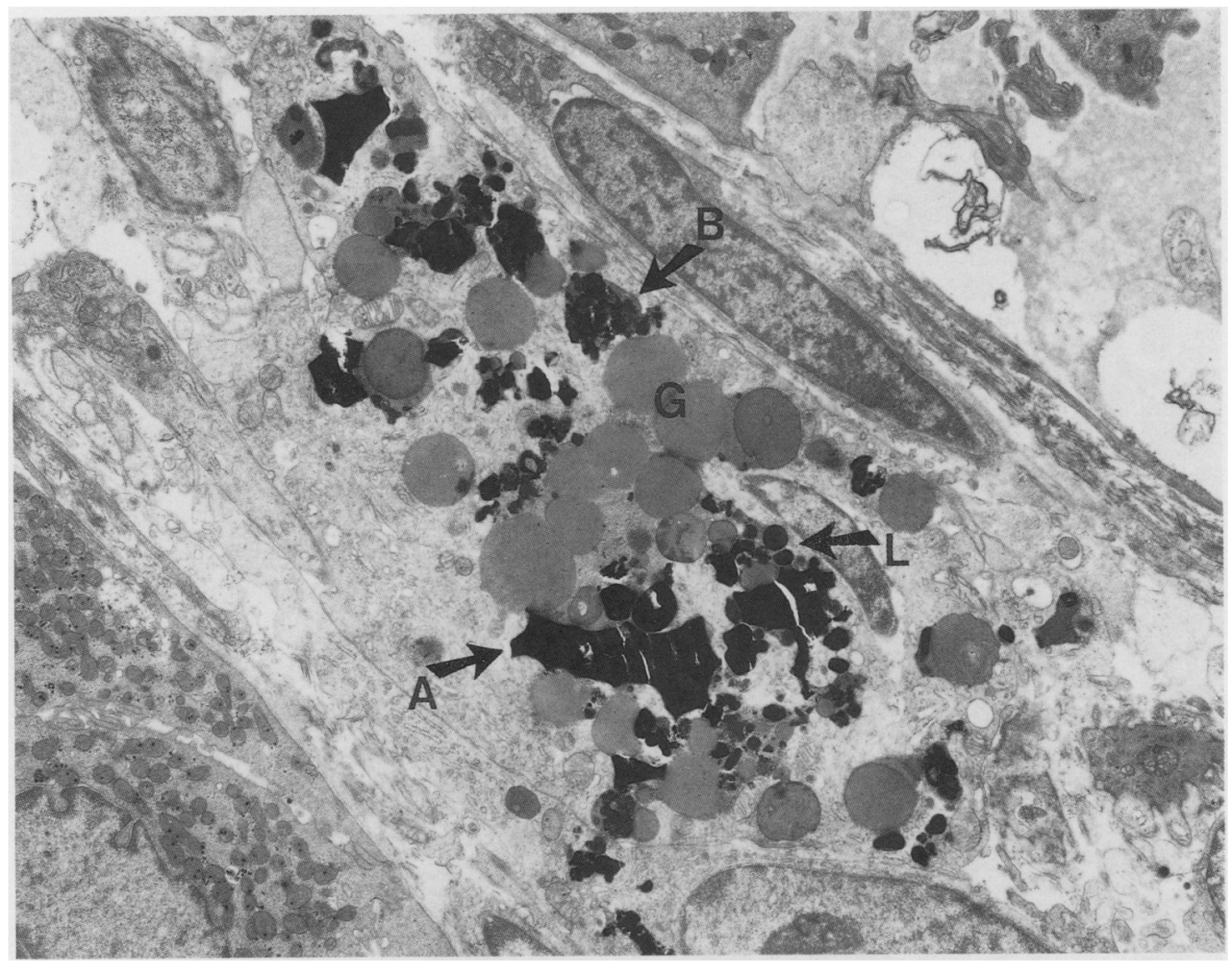

Fig. 3 Angular (arrow A) and irregularly shaped (arrow B) electron dense bodies in patient 8. Note the lipid droplets (arrow $L$ ) and secretory granules $(G)$.

laneous conditions were positive (grade $1+21$ cases; grade $2+1$ case). The difference between dialysis patients and control patients was statistically significant $(p<0 \cdot()() 1)$.

(Of the 47 biopsies examined independently by two pathologists there was total agreement in $40(85 \%)$. In six $(1.3 \%)$ there was a difference of one grade while in one $(2 \%)$ there was a difference of two grades.

\section{Discussion}

Since the first description of duodenal 'melanosis' in 1976 'seven other cases have been reported." * Because the pigment stained positively with the Masson-Fontana method several early workers considered it to be melanin. Although it is extensively used for the identification of melanin in routine histopathological work, however, it is not specific because other reducing substances - for example, argentaffin cell granules, will also stain by this method. Cowen and Humphries noted that even though the pigment stained positively with the Masson-Fontana method, its iron content was demonstrable both by histochemical staining and by microincineration. Sharp et al also noted that the duodenal pigment was not identical with melanin.: Pounder et al recently carried out electron probe xray analysis on material from their patient and confirmed the presence of iron." Because this iron occurred in the sulphide form, a negative reaction was obtained using Perls' stain. They speculated that under certain circumstances this iron sulphide could be oxidised to iron oxide. This was confirmed by the findings of Yamase et al. " Their patient's pigment was negative on Perls' stain initially but became positive on follow up. Steckman and Bozymski described another patient in whom the duodenal pigment stained strongly for iron but was negative using the Masson-Fontana method.

Our findings have extended the observations of these earlier workers. Pigment which stained positively with the Masson-Fontana method but nega- 


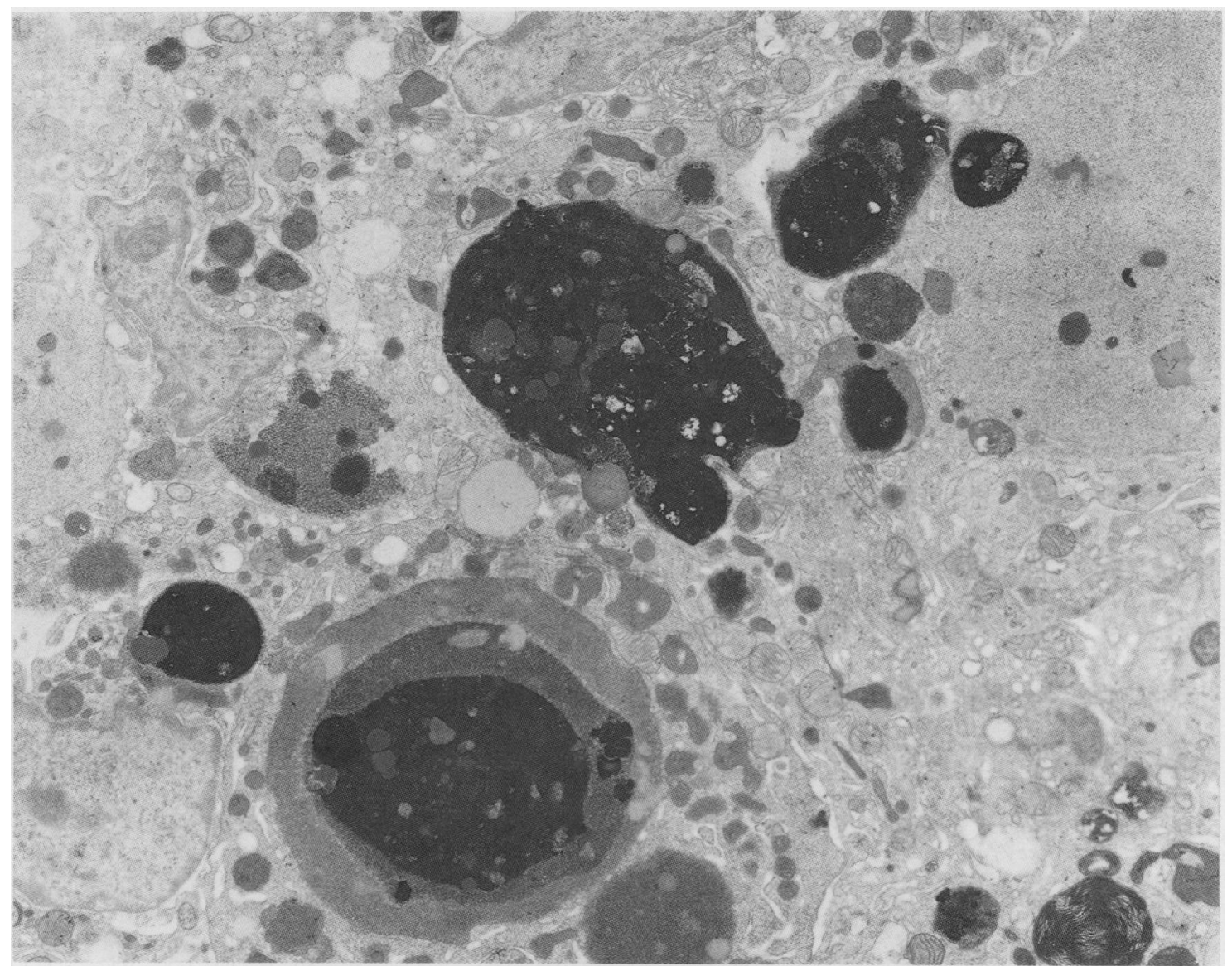

Fig. 4 Electron dense structures with lysosomal bodies in patient 3.

tively with Perls" stain was shown to be caused by angular electron dense particles similar to those described by Sharp.: Pounder" and Yamase." Electron probe $\mathrm{x}$-ray analysis showed the presence of iron and sulphur in these granules, confirming Pounder's result.

It is not clear why a pigment which seemed identical on electron microscopy should give a positive result with the Masson-Fontana method in Sharp's patient ${ }^{2}$ as well as ours: but not in those of Pounder" and Yamase." We agree with Pounder." however. that this stain was difficult to interpret because of the naturally dark colour of the pigment.

In contrast, the pigment in patients 3 and 5 , which was positive with Perls' stain but negative by the Masson-Fontana method, was shown to be because of more rounded particles, also electron dense. While the angular particles contained a high proportion of sulphur in addition to iron. however, the rounded particles contained iron but little or no sulphur.
Our findings in patient 8 also indicate that pigment which stained positively with Perls" stain can change in time to stain positively with the Masson-Fontana method. It is possible that this change occurs when sufficient amounts of sulphur become incorporated into the pigment. Our patients, and those reported in the literature, therefore, seem to form a continuous spectrum. While the duodenal pigment probably contained iron in all cases, it displayed varying histochemical characteristics perhaps depending on the amount of sulphur present.

The duodenal pigment in our patients differs from melanin in that melanin does not contain iron." Also, melanocytes do not occur in gastroduodenal mucosa. ${ }^{\text {II" }}$ The pigment also seemed to be different from that of melanosis coli. This latter condition has been shown to be the result of the deposition of a mixture of lipofuscin and melanin. although in some cases iron has also been shown." "While the term 'melanosis coli' is a misnomer it has become accepted through prolonged usage. In the case of duodenal 


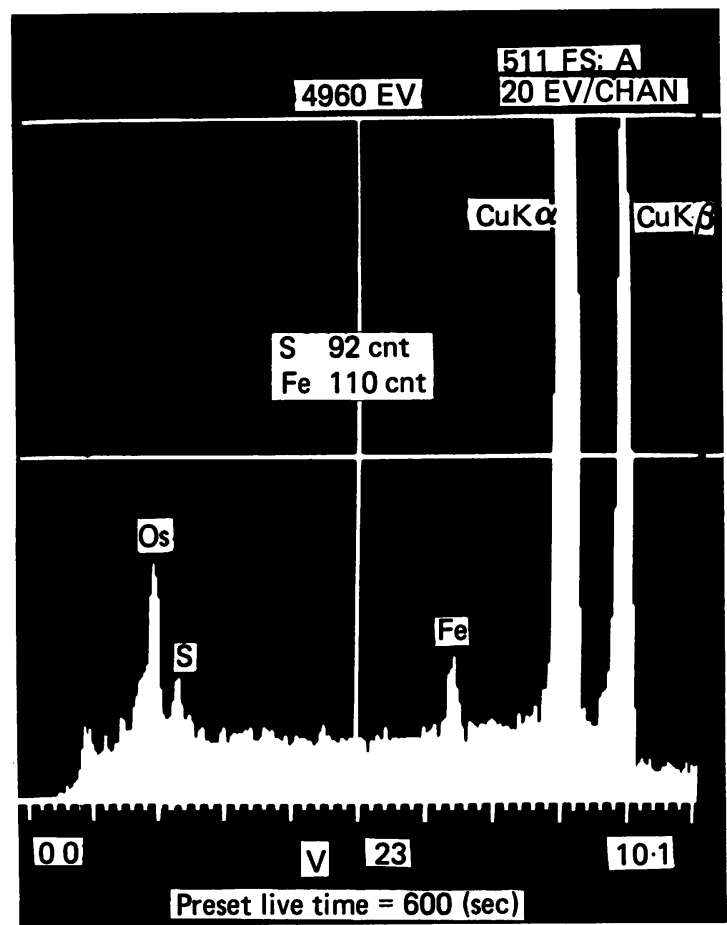

Fig. 5 Spectrum from angular bodies of patient 8 (corresponding to Fig. 3). Peaks of iron (Kat $6.40 \mathrm{keV}$ ) and sulphur (Kat 2.31 keV) are shown.

pigmentation the term 'duodenal pseudomelanosis' would seem more appropriate.

Three of the eight previously recorded cases of duodenal pseudomelanosis were patients with chronic renal failure, three other patients were anaemic, two had chronic gastric ulcer, two had gastric polyps, and two patients have suffered gastrointestinal bleeding. In the present series, seven patients had endstage renal failure on maintenance dialysis treatment, one patient had received a renal transplant after having been on chronic dialysis for endstage renal disease while the last patient presented with anaemia. It seems therefore that an association exists between duodenal pseudomelanosis and chronic renal failure. Although five of the eight patients in the literature, and seven of our nine patients have also been on various hypertensive medications, this may merely be an indication of the frequency of hypertension in uraemic subjects. All our chronic renal failure patients received iron supplements. Our ninth patient, being anaemic, could also have received previous iron treatment. Of the eight patients previously reported one was stated to have been taking iron. Therefore duodenal pseudomelanosis may also be associated with the use of oral iron supplements.

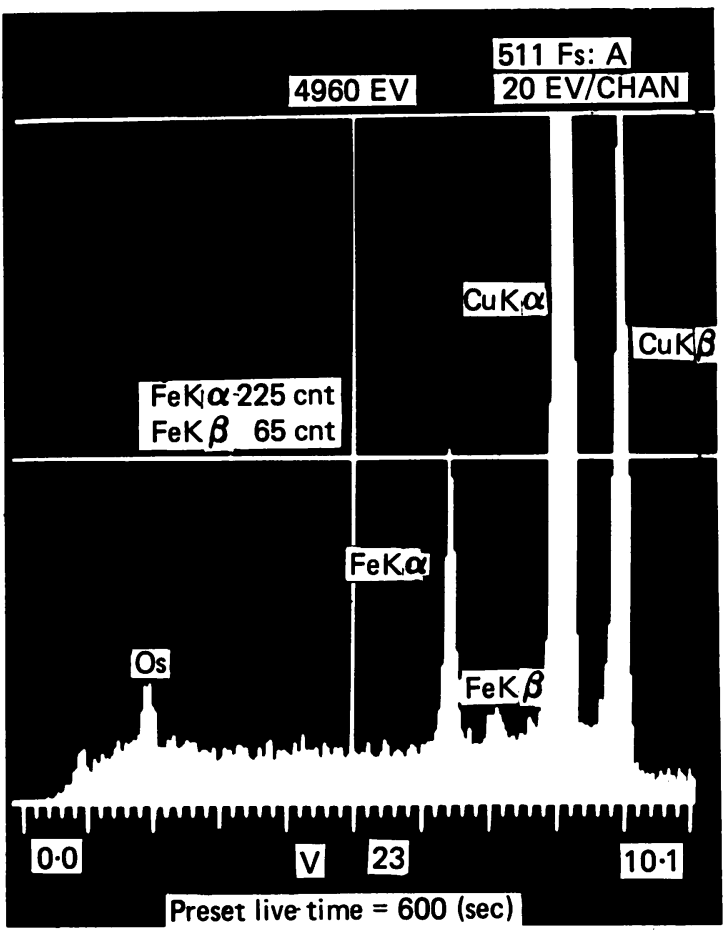

Fig. 6 Spectrum from irregular structures with lysosomal bodies in patient 3 (corresponding to Fig. 4). Peaks of iron (K at $6.40 \mathrm{keV}$ and $\mathrm{K \beta}$ at $7.06 \mathrm{keV}$ ) are shown.

Our postulate is that duodenal pseudomelanosis begins with the deposition in the mucosa of iron which stains positively with Perls' stain. This would correspond to the rounded structures seen on electron microscopy in patients 3 and 5 . In some patients, however, sulphur becomes incorporated into the granules. This may alter the staining characteristics of the pigment so that it reacts positively with the Masson-Fontana method. This would correspond to the angular structures seen under the electron microscope in patients $1,6,7$, and 8 (second biopsy). The transition from one type of pigment to the other occurred in patient 8 . Established deposition with Perls' positive pigment can regress, as in patient 5 . Disappearance of duodenal pigment also occurred in Sharp's patient, ' while in Yamase's patient, pigment which initially stained negatively for iron became positive 17 months later."

Iron in the duodenal mucosa could come either from intramucosal haemorrhage or luminal absorption. The chances of intramucosal haemorrhage should theoretically be increased in patients on chronic haemodialysis, as these patients are routinely heparinised. We consider this explanation unlikely for the following reasons, however: (1) intramucosal haemorrhage should occur as frequently in the 
stomach as in the duodenum. Deposition of iron in the gastric mucosa appears to be less common, however, occurring in only 12 of 51 patients $(24 \%)$. In all 12 cases the amount of iron was small - that is $1+$. (2) In an endoscopic study of 110 patients on chronic haemodialysis we did not find petechiae or purpura in the duodenal mucosa. In contrast, petechial spots were found in the gastric mucosa in 28 of 120 cases. (3) Our patients 5, 6, and 7 were on chronic ambulatory peritoneal dialysis and no heparinisation was involved. (4) The proximal duodenum which is involved in duodenal pseudomelanosis is also the site of maximal iron absorption. ${ }^{13}$

We consider it more likely that the iron deposition came from luminal absorption. Impairment of subsequent transport would then result in its accumulation. All our patients on haemodialysis were on iron supplements and it seems likely that this was the cause of duodenal mucosal iron deposition seen in $71 \%$ of cases. The quantity of iron deposited presumably determined whether or not the pigment was macroscopically visible. The staining characteristics of the pigment on the other hand might be related to the amount of sulphur present in the pigment. The source of the sulphur is uncertain but may be derived from the diet. Haemosiderin and ferritin are also known to contain a small amount of sulphur. ${ }^{14}$

Further studies on duodenal pseudomelanosis may advance our understanding of iron metabolism in patients with renal failure.

The authors would like to thank Dr C H Lim, Head of the Department of Renal Medicine, Singapore General Hospital for allowing them to study his patients, Ms G L Loy for technical assistance, and staff nurse Tan Choon Sung for her help. This study was presented to the Autumn meeting of the British Society of Gastroenterology, September 1986.

\section{References}

1 Bisordi WU, Kleinman MS. Melanosis duodeni. Gastrointest Endosc 1976; 23: 37-8.

2 Sharp JR, Insalaco SJ, Johnson LF. 'Melanosis' of the duodenum associated with a gastric ulcer and folic acid deficiency. Gastroenterology 1980; 78: 366-9.

3 Ganju S, Adomavicius J, Salgia K, Steigmann F. The endoscopic picture of melanosis in the duodenum. Gastrointest Endosc 1980; 26: 44-5.

4 Breslaw L. Melanosis of the duodenal mucosa. Gastrointest Endosc 1980; 26: 45-6.

5 Cowen ML, Humphries TJ. Pseudomelanosis of the duodenum. Gastrointest Endosc 1980; 26: 107-8.

6 Pounder DJ, Ghadially FN, Mukherjee TM, et al. Ultrastructure and electron-probe X-ray analysis of the pigment in melanosis duodeni. J Submicroscopic Cytol 1982; 14: 389-400.

7 Steckman M, Bozymski EM. Haemosiderosis of the duodenum. Gastrointest Endosc 1982; 28: 145.

8 Yamase H, Norris M, Gillies C. Pseudomelanosis duodeni: a clinicopathological entity. Gastrointest Endosc 1985; 31: 83-6.

9 Lillie RD. Histochemistry of melanins. In: Wolman M, ed. Pigments in pathology. New York: Academic Press, 1969: 327-35.

10 Breathnach AS. Normal and abnormal melanin pigmentation of the skin. In: Wolman M, ed. Pigments in pathology. New York: Academic Press, 1969: 354-5.

11 Fisher ER. Pigmentation of the intestinal tract. In: Wolman M, ed. Pigments in pathology. New York: Academic Press, 1969: 492-8.

12 Ghadially FN, Parry EW. An electron-microscope and histochemical study of melanosis coli. J Pathol Bacteriol 1966; 92: 313-7.

13 Wheby MS. Site of iron absorption in man. Scand J haematol 1970; 7: 56-62.

14 Sturgeon P, Shoden A. Haemosiderin and ferritin. In: Wolman M, ed. Pigments in pathology. New York: Academic Press, 1969; 93-114. 